\title{
The Rarest of the Rare: A Case of Primary Cardiac Osteosarcoma With a Review of the Literature
}

\author{
Hemendra Mhadgut $^{1}$, Sukesh Manthri ${ }^{1}$, Bahaaeldin Youssef ${ }^{2}$, Devapiran Jaishankar ${ }^{1}$ \\ 1. Medical Oncology, East Tennessee State University, Johnson City, USA 2. Pathology, East Tennessee State University, \\ Johnson City, USA
}

Corresponding author: Hemendra Mhadgut, hemen712@gmail.com

\begin{abstract}
A 54-year-old female presented with shortness of breath and cyanosis. Work up with chest X-ray and subsequent echocardiogram revealed an intracardiac bi-atrial mass leading to emergent cardiothoracic resection. Pathology was consistent with a primary cardiac high-grade osteosarcoma. Post-resection staging positron emission tomography-computed tomography (PET-CT) showed hypermetabolic mixed lytic and sclerotic lesion of T10 concerning for metastasis. She received five cycles of adriamycin and ifosfamide chemotherapy before discontinuation due to systolic dysfunction. Nine months later, she developed a high tumor burden with progressive disease and was treated with second-line gemcitabine/docetaxel with disappointing results. She is currently on treatment with cyclophosphamide and topotecan as third-line treatment with an excellent clinico-radiographic response. Osteosarcomas are aggressive with a high incidence of recurrence and metastasis. Fewer than 50 cases of primary cardiac osteosarcomas have been reported in the literature. Even though complete resection can be achieved in some cases, long-term results are usually poor. No standard therapy has been established.
\end{abstract}

Categories: Cardiac/Thoracic/Vascular Surgery, Cardiology, Oncology

Keywords: osteosarcoma, cardiac tumors, sarcomas, systemic chemotherapy, resection

\section{Introduction}

Metastatic tumors of the heart are more common than primary tumors. The frequency of primary cardiac tumors is $0.001 \%-0.03 \%$ in an autopsy series [1]. About $75 \%$ of these primary cardiac tumors are benign tumors such as myxoma, lipoma, papillary fibroelastoma, and rhabdomyoma [2]. The most frequently reported malignant primary cardiac tumors are sarcomas. Angiosarcomas and myxofibrosarcomas are the most common sarcomas of the heart [3]. Cardiac osteosarcoma, however, is extremely rare. We present a rare case of bi-atrial high-grade osteosarcoma [4]. This case was previously presented as a meeting abstract at the Appalachian Student Research Forum in April, 2020.

\section{Case Presentation}

Review began 06/10/2021 Review ended 06/29/2021 Published 07/19/2021

\section{๑) Copyright 2021}

Mhadgut et al. This is an open access article distributed under the terms of the Creative Commons Attribution License CC-BY 4.0., which permits unrestricted use, distribution, and reproduction in any medium, provided the original author and source are credited.
A 54-year-old Hispanic female presented with shortness of breath and was cyanotic on examination while visiting Mexico. Work up included an abnormal chest X-ray, echocardiogram concerning for bi-atrial myoma leading to a cardiothoracic surgical referral. She underwent bi-atrial intracardiac tumor resection in Mexico. Several months prior to her resection, she noted numbness on the side of the face evaluated by her physicians in the United States with a brain MRI and carotid ultrasound/Doppler that was unrevealing. She also remembered an episode of uncontrolled hypertension two years prior to surgery requiring admission to a local hospital in East Tennessee with a cardiology evaluation. Surgical pathology showed extensive undifferentiated spindle cell proliferation with multifocal osteoid production and foci of osseocartilaginous differentiation (Figure 1). There were prominent necrosis and a moderately high mitotic rate (10-19/HPF). Tumor cells were positive for SatB2 and negative for vascular, muscular, or neural markers. This is consistent with a primary cardiac high-grade osteosarcoma. These occur very rarely, usually in the atria, and behave aggressively. Post-resection staging positron emission tomography-computed tomography (PET-CT) showed hypermetabolic mixed lytic and sclerotic lesion of T10 concerning for metastatic disease. 


\section{Cureus}

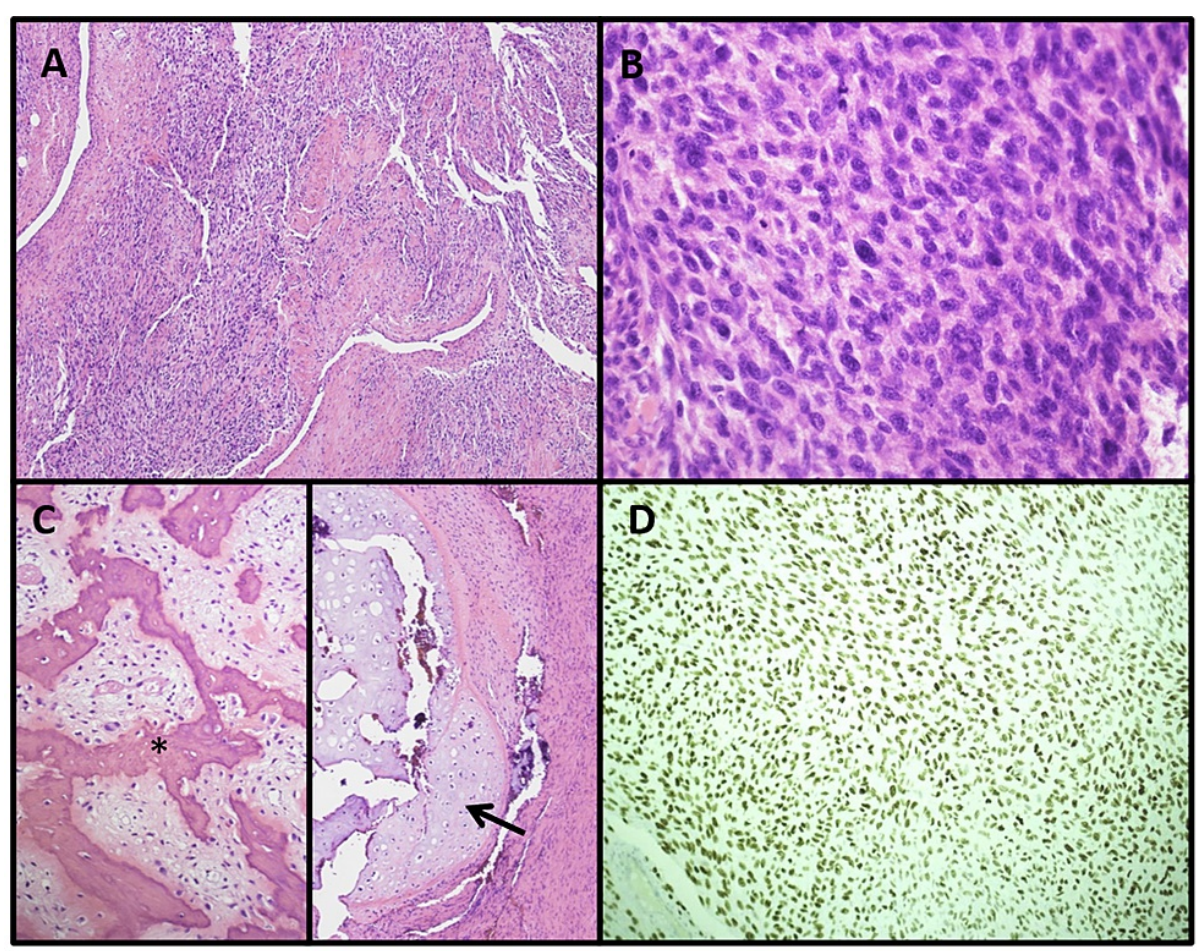

Figure 1. H\&E stain at 40x magnification showing a high grade spindle cell neoplasm infiltrating cardiac muscle (A). At 400x magnification the tumor is composed of atypical ovoid cells with inconspicuous cell borders, eosinophilic cytoplasm, hyperchromatic nuclei, prominent nucleoli, and scattered mitoses (B). Osteoblastic (asterisk) and chondroblastic (arrow) foci are seen (C). Tumor cells show strong, diffuse, nuclear positivity with SATB2 immunohistochemical stain, supporting the diagnosis of osteosarcoma (D).

FIGURE 1: Pathology description

She received five cycles of adriamycin and ifosfamide chemotherapy. Adriamycin was discontinued due to left ventricular dysfunction with an ejection fraction of 30\%-35\%, multiple segmental abnormalities, diffuse left ventricular hypokinesis, and moderate to severe mitral valve regurgitation.

Despite intracardiac tumor, resection, concern for metastatic disease, chemotherapy, and systolic dysfunction, the patient was asymptomatic and had a robust performance status. A follow-up PET-CT five months after cessation of treatment did not show any evidence of new metastatic disease other than abnormalities in the T10 vertebra (Figure 2). 


\section{Cureus}

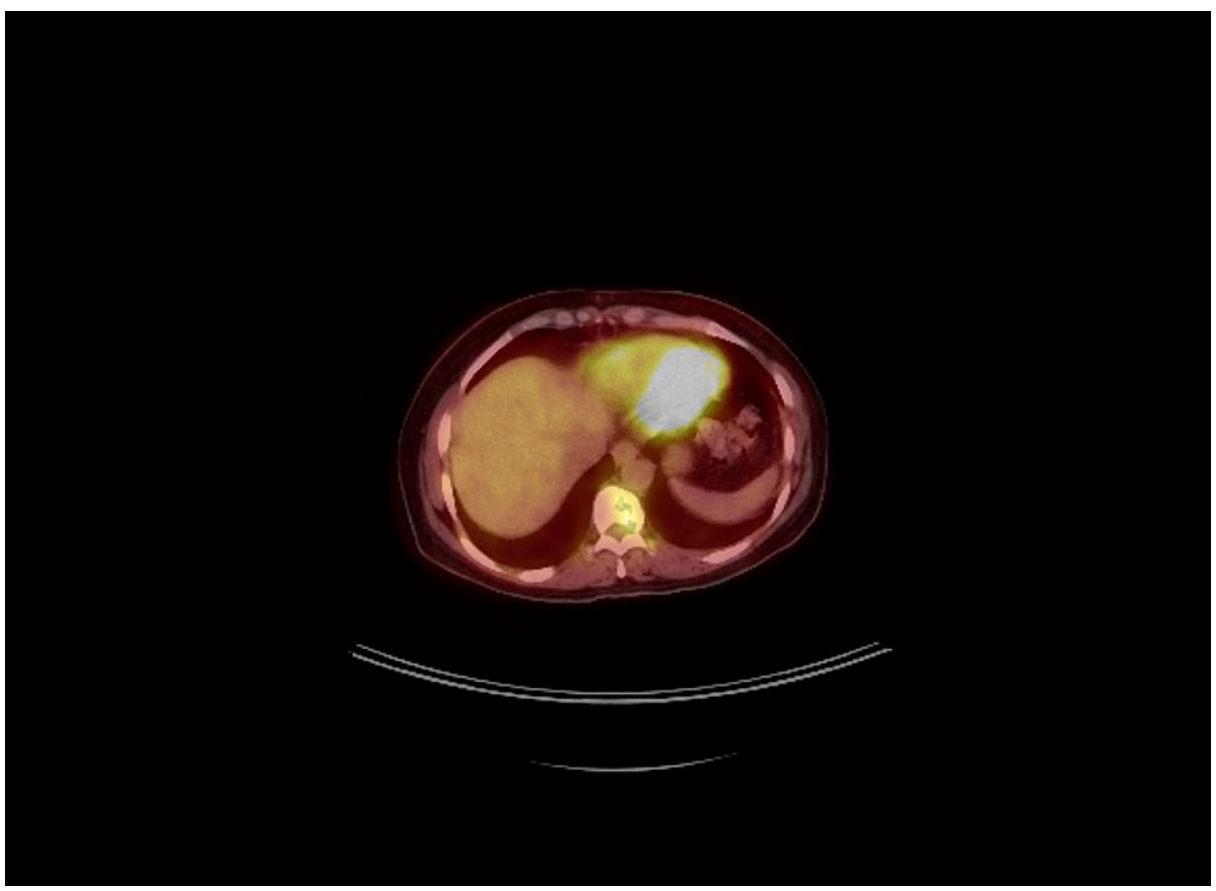

FIGURE 2: Post adjuvant therapy PET-CT with the hyper-metabolic T10 vertebra lesion

A repeat echocardiogram continued to reveal a depressed ejection fraction of $35 \%$. A surveillance CT nine months after cessation of treatment revealed a $3.25 \mathrm{~cm}$ mass over the left rectus abdominis, a $2.2 \mathrm{~cm}$ subcutaneous lesion around T12, and a $4.4 \mathrm{~cm}$ mass medially in the left adductor muscle (Figure 3).

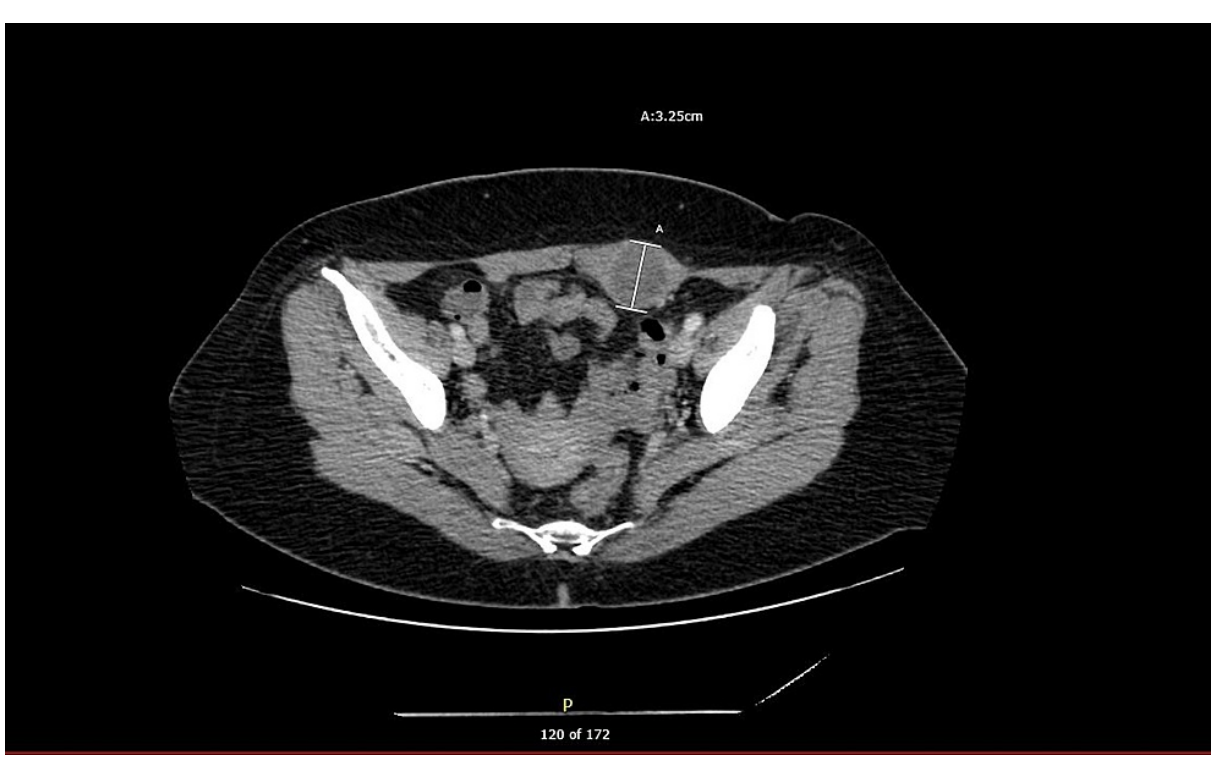

FIGURE 3: CT abdomen/pelvis with contrast for surveillance showing a $3.25 \mathrm{~cm}$ lesion in the left rectus abdominis

Biopsy of these lesions confirmed high-grade osteosarcoma. She received gemcitabine and docetaxel as second-line therapy. Restaging scans after three cycles revealed explosive progression of the disease (Figure $4)$. 


\section{Cureus}

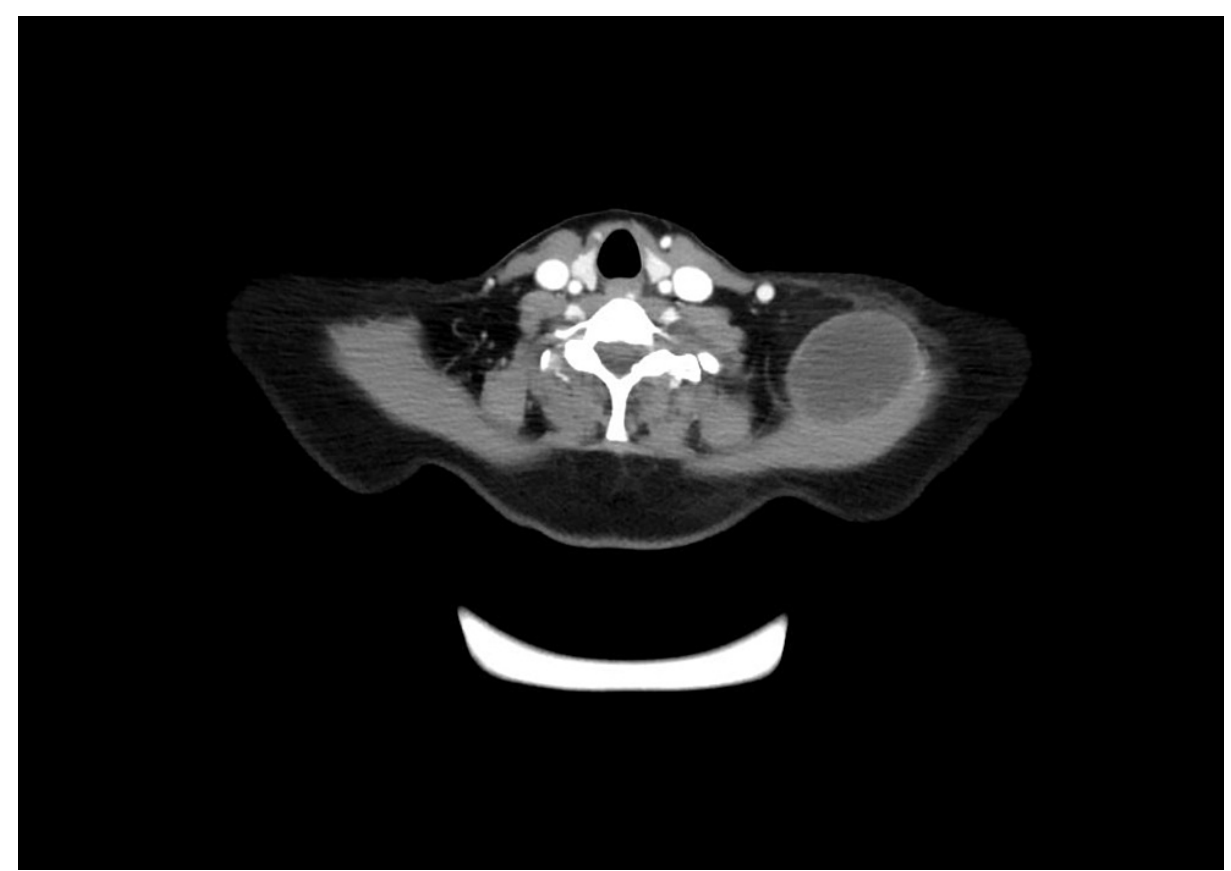

FIGURE 4: CT of chest/abdomen/pelvis showing progressive disease with a $4.4 \times 5.5 \mathrm{~cm}$ left trapezius mass

She subsequently initiated cyclophosphamide and topotecan as third-line therapy and has had a dramatic response clinically and radiographically (Figure 5).

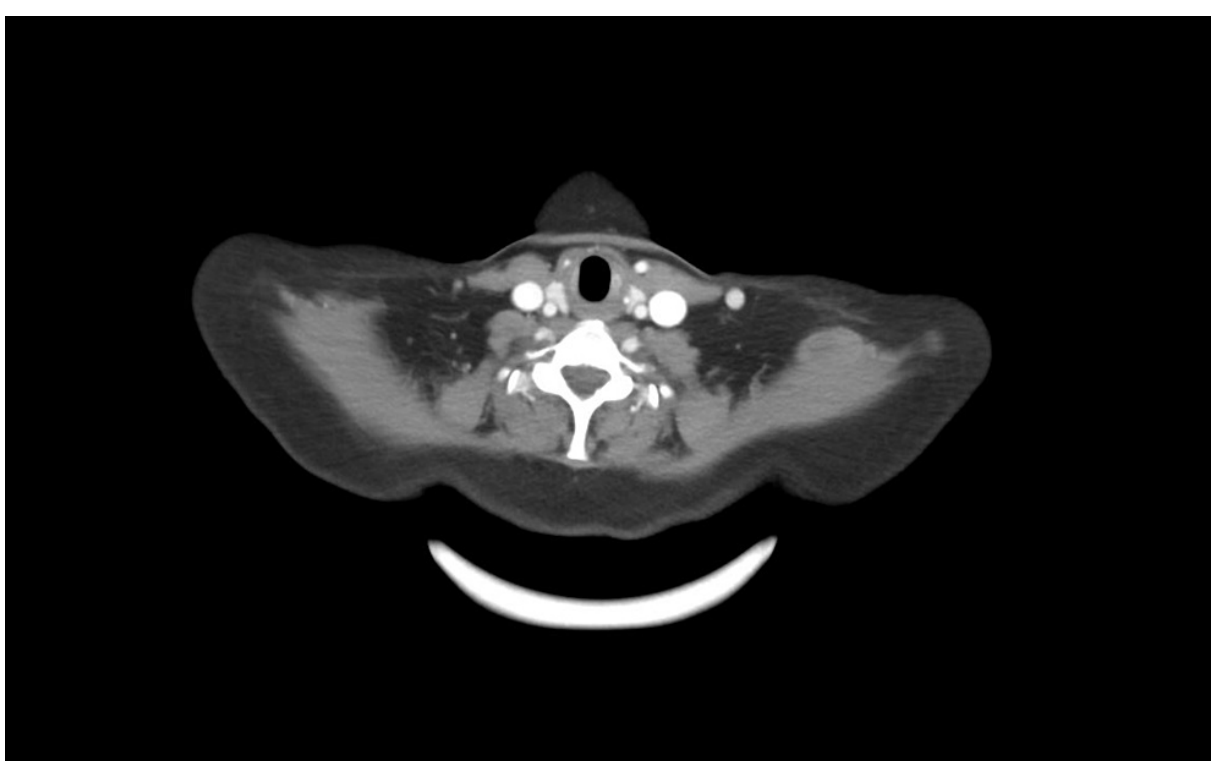

FIGURE 5: CT of chest/abdomen/pelvis with contrast showing disease response with the index lesion at the left trapezius decreased in size to $3.3 \times 1.9 \mathrm{cms}$

\section{Discussion}

Osteosarcoma is one of the most common primary skeletal tumors. Extra-skeletal osteosarcoma is relatively rare and is more often seen in lower extremity soft tissue. Cardiac osteosarcomas are extremely rare; they account for only 3\%-9\% of all cardiac sarcomas with the first case report in 1957 [5,6] (Figure 6). Fewer than 60 cases of primary cardiac osteosarcoma have been reported to date [6]. 


\section{Cureus}

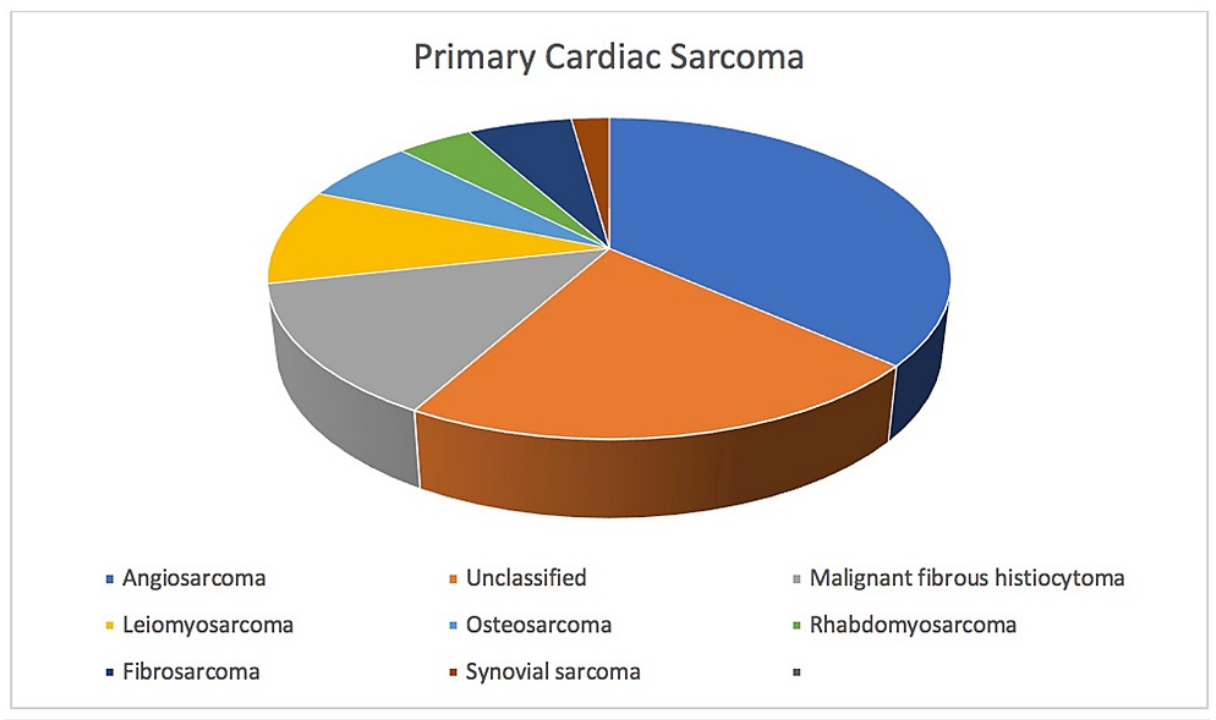

FIGURE 6: Incidence of primary cardiac sarcoma

Primary cardiac tumors present with a wide variety of symptoms and signs masquerading as cardiovascular disease, usually as a combination of syncope, heart failure, arrhythmia, or embolic event [7]. The most common presenting symptom is shortness of breath. Intracavitary tumors are more likely to cause heart failure as opposed to intramural tumors that have a predilection for arrhythmias. Embolization of tumor pieces and local invasion of vital structures can also cause symptoms. Mass effect, obstruction, or functional effects cause a wide spectrum of signs and symptoms in malignant cardiac tumors. These include neurological deficits, palpitations, cough, hemoptysis, pleural effusion, chest pain, syncope, ankle edema, elevated liver enzymes (in the presence of right heart failure), and other symptoms of heart failure, valve dysfunction, and thrombus/tumor embolization $[7,8]$.

Echocardiography is usually the initial imaging study performed to diagnose a cardiac tumor, however, CT and cardiac MRI offer distinct diagnostic advantages [9]. Echocardiography can evaluate the involvement of valves, size, and extension of the tumor. Benign tumors such as myxoma are pedunculated and usually on the left side whereas malignant tumors are often broad-based. Use of echocardiography contrast can help demonstrate the highly vascular nature of malignant tumors. A transesophageal echocardiogram is superior in diagnosing cardiac tumors located in the atrium. Echocardiography is usually followed by a CT or MRI which often provides a high degree of tissue characterization as well as assessment of calcification which can further aid in the diagnosis of these tumors. Cardiac osteosarcomas have been reported on cardiac CT as a low attenuation mass with dense calcification $[9,10]$ (Table 1 ).

\begin{tabular}{|l|l|l|l|l|}
\hline & $\begin{array}{l}\text { Mean age at diagnosis in } \\
\text { years }\end{array}$ & $\begin{array}{l}\text { Frequency in } \\
\%\end{array}$ & $\begin{array}{l}\text { Typical cardiac } \\
\text { location }\end{array}$ & Gender predilection \\
\hline $\begin{array}{l}\text { Angiosarcoma } \\
\text { Malignant Fibrous } \\
\text { histiocytoma }\end{array}$ & 44 & 36 & Right heart & $\begin{array}{l}\text { No gender } \\
\text { predilection }\end{array}$ \\
\hline $\begin{array}{l}\text { Rhabdomyosarcoma } \\
\text { Osteosarcoma }\end{array}$ & 20 & 12 & Left atrium & $\begin{array}{l}\text { No gender } \\
\text { predilection }\end{array}$ \\
\hline Lymphoma & 38 & 5 & $\begin{array}{l}\text { No particular } \\
\text { preference }\end{array}$ & $\begin{array}{l}\text { No gender } \\
\text { predilection }\end{array}$ \\
\hline
\end{tabular}

\section{TABLE 1: Primary cardiac malignant tumor characteristics}

The treatment of primary cardiac tumors depends on location, size, histology, and metastatic spread. For treatment purposes, cardiac sarcomas are divided based on location into the right heart, left heart, and pulmonary artery sarcomas [11]. The main modality of treatment for primary cardiac tumors is surgical 
resection. Benign cardiac tumors such as myxomas are usually treated with surgical excision followed by clinical surveillance with imaging studies. Cardiac sarcomas have a poor prognosis as reported in many case studies, with a median survival of 6-25 months [10-12]. Radiotherapy is avoided in left and right heart tumors given the risk of myocardial toxicity, however, it can be used in the treatment of pulmonary artery sarcoma [11]. Given the rarity of cardiac sarcomas, there is a paucity of prospective randomized data on the efficacy of adjuvant chemotherapy or radiotherapy in addition to surgery. Based on limited evidence, multiagent chemotherapy appears to be more effective, with doxorubicin, cisplatin, ifosfamide, taxanes, and gemcitabine having activity. A single-institution study done at a tertiary care center showed the most common first-line chemotherapy regimen included doxorubicin at $75 \mathrm{mg} / \mathrm{meter}$ sq given over 72 hours as a continuous infusion in combination with ifosfamide $10 \mathrm{~g} /$ meter sq divided over 4-5 days whereas gemcitabine $675-900 \mathrm{mg} / \mathrm{meter} s q$ on day 1 and day 8 with docetaxel $60-100 \mathrm{mg} / \mathrm{meter}$ sq on day 8 was the second most common regimen [8]. There is no evidence available on the use of neoadjuvant chemotherapy although theoretically it would be advantageous in obtaining clear surgical margins and help determine tumor response to therapy. This approach will need to be balanced with the urgency of the clinical presentation as in our case.

\section{Conclusions}

Primary cardiac tumors are highly variable in presentation with non-specific symptoms, and have a poor overall prognosis. Given its rare nature, there is insufficient data to guide its management. Surgery remains the cornerstone in the treatment of cardiac sarcoma whereas the role of neoadjuvant and adjuvant chemotherapy requires further investigation.

\section{Additional Information \\ Disclosures}

Human subjects: Consent was obtained or waived by all participants in this study. Conflicts of interest: In compliance with the ICMJE uniform disclosure form, all authors declare the following: Payment/services info: All authors have declared that no financial support was received from any organization for the submitted work. Financial relationships: All authors have declared that they have no financial relationships at present or within the previous three years with any organizations that might have an interest in the submitted work. Other relationships: All authors have declared that there are no other relationships or activities that could appear to have influenced the submitted work.

\section{References}

1. Burke A, Virmani R: Tumors of the Heart and Great Vessels (Atlas of Tumor Pathology 3rd Series) . Armed Forces Institute of Pathology, Washington DC; 1996.

2. Vander Salm TJ: Unusual primary tumors of the heart . Semin Thorac Cardiovasc Surg. 2000, 12:89-100 10.1053/ct.2000.5080

3. Zhang PJ, Brooks JS, Goldblum JR, et al.: Primary cardiac sarcomas: a clinicopathologic analysis of a series with follow-up information in 17 patients and emphasis on long-term survival. Hum Pathol. 2008, 39:138595. 10.1016/j.humpath.2008.01.019

4. 2020 ASRF presentations. (2020). Accessed: March 10, 2021: https://dc.etsu.edu/asrf/2020/presentations/13/..

5. Burke AP, Virmani R: Osteosarcomas of the heart. Am J Surg Pathol. 1991, 15:289-95. 10.1097/00000478199103000-00009

6. Aguilar CA, Donet JA, Galarreta CI, Yabar A: A primary cardiac osteosarcoma: case report and review of the literature. J Cardiol Cases. 2013, 7:e29-e33. 10.1016/j.jccase.2012.09.010

7. Simpson L, Kumar SK, Okuno SH, Schaff HV, Porrata LF, Buckner JC, Moynihan TJ: Malignant primary cardiac tumors: review of a single institution experience. Cancer. 2008, 112:2440-6. 10.1002/cncr.23459

8. Yusuf SW, Bathina JD, Qureshi S, et al.: Cardiac tumors in a tertiary care cancer hospital: clinical features, echocardiographic findings, treatment and outcomes. Heart Int. 2012, 7:e4. 10.4081/hi.2012.e4

9. Paraskevaidis IA, Michalakeas CA, Papadopoulos CH, Anastasiou-Nana M: Cardiac tumors. ISRN Oncol. 2011, 2011:208929. 10.5402/2011/208929

10. Wang JG, Liu B, Gao H, Li YJ, Zhao P, Liu XP: Primary cardiac osteosarcoma. Heart Lung Circ. 2016, 25:698704. 10.1016/j.hlc.2016.01.006

11. Bakaeen FG, Jaroszewski DE, Rice DC, et al.: Outcomes after surgical resection of cardiac sarcoma in the multimodality treatment era. J Thorac Cardiovasc Surg. 2009, 137:1454-60. 10.1016/j.jtcvs.2008.11.026

12. Fujino S, Miyoshi N, Ohue M, et al.: Primary osteosarcoma of the heart with long-term survival: a case report of laparoscopic resection of a metastatic sarcoma in the intestine. Oncol Lett. 2014, 8:1599-602. 10.3892/ol.2014.2405 